\title{
Role of Ultrasound and Color Flow Doppler in Diagnosis of Intrauterine Growth Restriction
}

\author{
Medhat M. Refaat, Ahmed E. Shalaan, Radwa N. Afifi
}

\begin{abstract}
Department of Radiology, Benha faculty of medicine, Benha University, Egypt.

Correspondence to: Radwa N. Afifi, Department of Radiology, Benha faculty of medicine, Benha University, Egypt
\end{abstract}

Email:

thegoldlione2050@gmail.com

Received: 13 September 2019

Accepted: 12 June 2021

\begin{abstract}
:
Background: Multi-vessel Doppler ultrasonography is the principal surveillance tools in pregnancies complicated by fetal growth restriction. Objective: To determine diagnostic accuracy of the fetal umbilical artery, middle cerebral artery pulsatility indices and their ratio in intrauterine growth restricted fetuses. Patients \& Methods: Forty patients were studied that had been diagnosed clinically and ultrasonographically as intra-uterine growth restriction (IUGR). All patients in the study underwent uniform antenatal assessment protocol that includes umbilical artery (UA) and middle cerebral artery (MCA) Doppler ultrasound studies. These were conducted either twice weekly or daily according to the severity of the condition. Results: Abnormal UA PI was found in 25 cases, 11cases due to maternal cause, 5 cases due to placental cause, and 9 cases with idiopathic cause of the IUGR group. Abnormal MCA PI was
\end{abstract} found in 26 cases, 11 cases due to maternal cause, 5 cases due to placental cause, and 10 cases with idiopathic cause of the IUGR group. Abnormal C/U Ratio was found in 24 cases, 11 cases due to maternal cause, 5 cases due to placental cause, 8 cases with idiopathic cause of the IUGR group. Conclusion: Among the Doppler indices, the $\mathrm{C} / \mathrm{U}$ ratio is a better predictor of IUGR fetuses than either the UAPI or the MCA PI alone, with a high specificity and PPV. However, measurement of the UAPI (among all the Doppler indices) is enough to detect IUGR per se, probably because UAPI is a direct reflection of the resistance in the placental vascular bed.

Keywords: Doppler ultrasonography, middle cerebral artery, umbilical artery, pulsatility index, intra-uterine growth retardation. 


\section{Introduction}

Intra uterine growth restriction (IUGR) remains a significant cause of perinatal mortality, morbidity and childhood disability. IUGR is defined as sonographic estimated fetal weight $<10^{\text {th }}$ percentile for gestational age. (1).

Placental insufficiency is associated with the majority of cases of IUGR. There are numerous causes of IUGR which are not caused primarily by placental insufficiency as maternal disease, congenital anomalies, infection and drugs but indirectly lead to it (2).

Evaluation of placental function by umbilical artery Doppler is a clinical standard to diagnose IUGR. Ultrasound plays a number of important roles in the diagnosis and management of growth restriction Diagnosis of IUGR is based on fetal measurements, assessment of amniotic fluid volume, and other sonographic findings.

Currently, Ultrasonographic evaluation of the fetus is the preferred and accepted modality for the diagnosis of inadequate fetal growth. It offers the advantages of reasonably precise estimations of fetal weight, determination of interval fetal growth velocity, measurement of several fetal dimensions to describe the pattern of growth abnormality, and assist in the investigation of the etiology of restricted growth (3).

Doppler ultrasound plays a fundamental role in the diagnosis of IUGR fetuses and also has the potential to play an important role in timing the delivery of some IUGR fetuses. It allows the clinician to evaluate the circulation on both sides of the placenta and to judge on the fetal adaptive circulatory changes as a response to developing hypoxia. Although the fetal and placental circulations are a continuous unit, assessment of cardiovascular system can be subdivided into arterial and venous Doppler. The most commonly examined arterial vascular beds are the placenta (umbilical and uterine arteries) and the cerebral circulation. In addition, some changes occur in venous flow in the compromised fetus ant the most commonly examined venous vessels are the ducts venous, inferior vena cava and the umbilical vein (4).

As the possibility of efficiently treating growth restricted fetuses in utero are very limited, not to say nonexistent. Thus, the clinical management aims to deliver the IUGR fetus in time to avoid hypoxic damage to the fetus and eventually intrauterine death. There is general 
consensus that delivery is indicated when the risk of fetal death or significant morbidity from continued intrauterine existence is greater than the risk of prematurity

\section{Subjects and Methods}

The study was Prospective cohort study conducted in Benha Teaching Hospital. Patients were recruited from obstetrics and gynecology department in the period from June 2018 to March 2019. The study was done on 40 pregnancies that had been diagnosed clinically and ultrasonographically as intrauterine growth restriction (IUGR).The mean age of patient group is $26.60 \pm 3.001$ years old. The gestational age of the patients is 31-41 weeks as measured by last menstrual period. Written consents are taken from patients. Procedures are approved by ethical committee of the Benha Teaching Hospital.

\section{The criteria for study eligibility are:}

1. Gestational age determined by sure date of last menstrual period confirmed by ultrasound examination done before 20 weeks gestation.

2. Abdominal circumference (AC) and estimated fetal weight (EFW) by ultrasound less than $10^{\text {th }}$ percentile for gestational age.
3. Second and third trimesters of pregnancy.

All patients in the study underwent uniform antenatal assessment protocol that includes fetal biometry, $\mathrm{HC} / \mathrm{AC}$ ratio, $\mathrm{C} / \mathrm{U}$ ratio, umbilical artery (UA) middle cerebral artery (MCA) and uterine artery ( UTA ) Doppler ultrasound studies.

Doppler assessment: All examinations were performed using GE LOGIC 5, 7 and Toshiba scanner with $3.5 \mathrm{MHz}$ transducer. Doppler flow spectra were obtained from the UA at the midsection of the umbilical cord and the distal portion of the MCA. Pulsed wave Doppler measurements of UA and MCA were obtained using the pulsatility index (PI) to quantify arterial Doppler waveforms. The angle independent PI was calculated electronically from smooth curves fitted to good quality waveforms over three cardiac cycles according to the following formulae: $\mathrm{PI}=(\mathrm{S}-\mathrm{D}) / \mathrm{A}$

All recordings were obtained in the absence of fetal breathing and fetal movements. For each vessel, an average of three consecutive Doppler velocity waveform readings was used for statistical analysis. In the UA the presence, absence or reversal of end diastolic flow was noted, and the value of PI was recorded and compared with normal mean value for such gestational age. The 
MCA-PI was recorded and compared with normal mean value for such gestational age considering values greater than 2 standard deviations (SD) below the mean for gestational age as brain sparing, indicating abnormally reduced blood flow resistance.

The MCA PI / UA PI ratio (C/U Ratio) was calculated and a cut off value of 1.08 was considered, normal ratio $\geq 1.08$, abnormal ratio $<1.08$, according to 5 cut off point.

AFI of $5 \mathrm{~cm}$ or less was considered abnormal (oligohydramnios), while AFI more than $5 \mathrm{~cm}$ was defined as normal. Head circumference / Abdominal circumference ratio (HC/AC Ratio) was recorded and compared with normal mean value for such gestational age.

\section{Results:}

Statistical analysis:

The study group with IUGR were classified into 3 groups according to the cause of IUGR whether maternal, placental or idiopathic cause. The data collected throughout history taking, basic clinical examination and ultrasound and Doppler examination, then outcome measures coded, entered and analyzed using Microsoft excel software. Data then were inserted into Statistical Package of Social Science software (SPSS version 20) for statistical analysis.

According to the type of data; qualitative as number and percentage, quantitative data represented by mean $\pm \mathrm{SD}$. The following tests were used to test difference for significance; t-test $(\mathrm{t})$ and ANOVA test $(\mathrm{F})$ for quantitative independent data, Chi square test (X2) for difference and association of qualitative data.

P. value was set at $<0.05$ for significant result $\&<0.001$ for highly significant results.

Cut off values that could be differentiate between the causes of IUGR are generated using ROC curve.

The study was included 40 patients with IUGR of different causes. They were classified into 3 groups according to the cause of IUGR whether maternal 19(47.5\%), placental $5(12.5 \%)$ or idiopathic cause $16(40 \%)$. In the group of maternal causes:; 9 were hypertensive 7 were diabetic and 3 were diabetic \& hypertensive. 


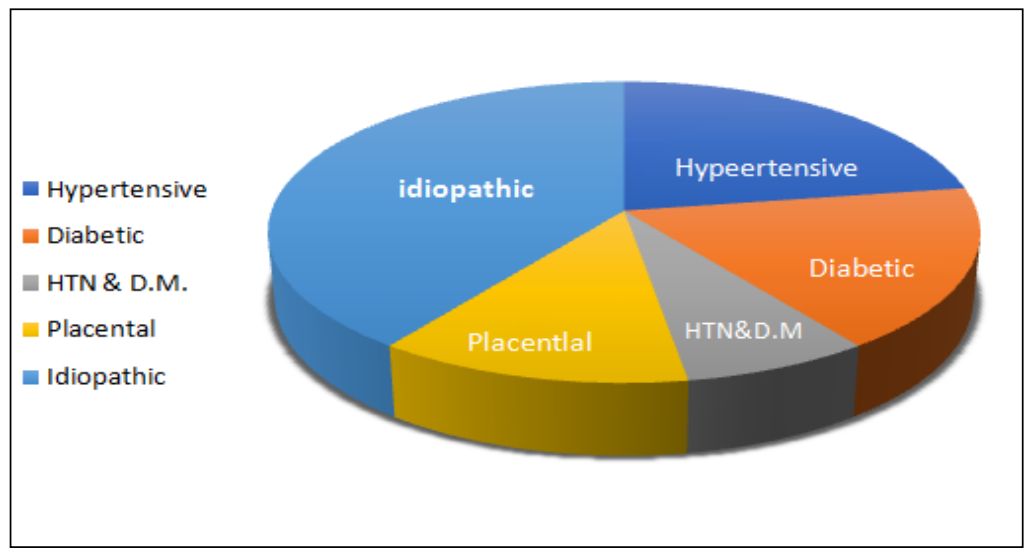

Fig. 1: Bie-chart showing the cause of IUGR

Table 1: Distribution of age among the studied groups

\begin{tabular}{lllll}
\hline & $\begin{array}{l}\text { Maternal } \\
(\mathbf{N}: 19)\end{array}$ & $\begin{array}{l}\text { Placental } \\
(\mathbf{N}: 5)\end{array}$ & $\begin{array}{l}\text { Idiopathic } \\
(\mathbf{N}: 16)\end{array}$ & $\begin{array}{l}\text { Total } \\
(\mathbf{N}: 40)\end{array}$ \\
\hline $\begin{array}{l}\text { Age } \\
(\text { mean } \pm \text { SD) }\end{array}$ & $29.42 \pm 2.79$ & $30.2 \pm 3.27$ & $30.3 \pm 2.47$ & $29.88 \pm 2.69$ \\
\hline
\end{tabular}

Table 2: Distribution of GA and retardation of growth by weeks among the groups

\begin{tabular}{lllllll}
\hline & $\begin{array}{l}\text { Maternal } \\
(\mathbf{N}: 19)\end{array}$ & $\begin{array}{l}\text { Placental } \\
(\mathbf{N}: 5)\end{array}$ & $\begin{array}{l}\text { Idiopathic } \\
(\mathbf{N}: 16)\end{array}$ & $\mathbf{F}$ & $\mathbf{P}$ & $\mathbf{S}$ \\
\hline $\begin{array}{l}\text { GA by LMP } \\
(\mathbf{m} \text { )an } \pm \text { SD) }\end{array}$ & $34.1 \pm 2.18$ & $37 \pm 2.55$ & 34.69 & 0.505 & 0.6 & $\mathrm{NS}$ \\
$\begin{array}{l}\text { GA by U/S } \\
(\mathbf{m} \text { )an } \pm \text { SD) }\end{array}$ & $29.68 \pm 2.08$ & $30.8 \pm 1.92$ & $30.25 \pm 2.46$ & 2.52 & 0.09 & $\mathrm{NS}$ \\
$\begin{array}{l}\text { Retardation } \\
\text { (mean } \pm \text { SD) }\end{array}$ & $4.42 \pm 0.84$ & $6.2 \pm 1.3$ & $4.44 \pm 0.96$ & 7.612 & $0.002^{*}$ & $\mathrm{~S}$ \\
\hline
\end{tabular}

No significant difference in GA by LMP and U/S-GA between the three groups, but there is significant difference in retardation between them, being significantly higher in placental cause than other two groups. 
Table 3: Distribution of HC/AC ratio among the different groups according to its state (abnormal or normal) and its values

\begin{tabular}{|c|c|c|c|c|c|c|c|c|}
\hline \multicolumn{9}{|c|}{ Groups } \\
\hline & & & Maternal & Placental & Idiopathic & $X^{-}$ & $\mathbf{P}$ & $S$ \\
\hline HC/AC & Abnormal & $\begin{array}{l}\mathbf{N} \\
\%\end{array}$ & $\begin{array}{l}2 \\
10.5 \%\end{array}$ & $\begin{array}{l}4 \\
80 \%\end{array}$ & 1 & & & \\
\hline & Normal & $\begin{array}{l}\mathrm{N} \\
\%\end{array}$ & $\begin{array}{l}17 \\
89.5 \%\end{array}$ & $\begin{array}{l}1 \\
20 \%\end{array}$ & $\begin{array}{l}15 \\
93.75\end{array}$ & 15.571 & $0.00^{* *}$ & HS \\
\hline Total & & $\begin{array}{l}N \\
5\end{array}$ & 19 & $\begin{array}{l}5 \\
100 \%\end{array}$ & 16 & & & \\
\hline
\end{tabular}

Table 4:Abnormal HC/AC ratio is highly significantly associated with placental cause of IUGR.

\begin{tabular}{lllll}
\hline Groups & $\begin{array}{l}\text { HC/AC ratio } \\
\text { mean } \pm \text { SD }\end{array}$ & t-test & P & S \\
\hline Maternal & $1.25 \pm 0.33$ & 0.479 & 0.6 & NS \\
Idiopathic & $1.2 \pm 0.26$ & & & \\
Placental & $1.94 \pm 0.49$ & 3.789 & $0.001^{* * *}$ & HS \\
Maternal & $1.25 \pm 0.33$ & & & HS \\
Placental & $1.94 \pm 0.49$ & 4.482 & $0.00^{* *}$ & \\
Idiopathic & $1.2 \pm 0.26$ & & & \\
\hline
\end{tabular}

No significant difference in $\mathrm{HC} / \mathrm{AC}$ ratio between maternal and idiopathic groups, but being significantly higher with placental cause compared to maternal and idiopathic causes.

Table 5: Distribution of amniotic fluid state among the 3 groups

\begin{tabular}{|c|c|c|c|c|c|c|c|c|}
\hline & & \multicolumn{4}{|c|}{ Groups } & \multirow{2}{*}{$X^{2}$} & \multirow{2}{*}{$\mathbf{P}$} & \multirow{2}{*}{$\mathbf{S}$} \\
\hline & & & Maternal & Placental & Idiopathic & & & \\
\hline Amniotic & Oligohydramnios & $\begin{array}{l}\mathbf{N} \\
\%\end{array}$ & $\begin{array}{l}10 \\
52.6 \%\end{array}$ & $\begin{array}{l}5 \\
100 \%\end{array}$ & $\begin{array}{l}4 \\
25 \$\end{array}$ & & & \\
\hline fluid & Normal & $\begin{array}{l}\mathbf{N} \\
\%\end{array}$ & $\begin{array}{l}9 \\
47.4 \%\end{array}$ & $\begin{array}{l}\mathbf{0} \\
0 \%\end{array}$ & $\begin{array}{l}12 \\
75 \%\end{array}$ & 8.975 & $0.01^{*}$ & $\mathbf{S}$ \\
\hline Total & & $\begin{array}{l}N \\
5\end{array}$ & $\begin{array}{l}19 \\
100 \%\end{array}$ & $\begin{array}{l}5 \\
100 \%\end{array}$ & $\begin{array}{l}16 \\
100 \%\end{array}$ & & & \\
\hline
\end{tabular}

Oligohydramnios significantly associated with placental cause of IUGR

Table 6:Sensitivity and specificity of cut off values of different Doppler and U/S indices for differentiation of placental cause of IUGR from maternal and idiopathic causes of IUGR :

\begin{tabular}{llll}
\hline & Cut off value & Sensitivity & Specificity \\
UA PI & $>1.88$ & $100 \%$ & $57.1 \%$ \\
MCA PI & $<1.12$ & $100 \%$ & $80 \%$ \\
C/U ratio & $<0.63$ & $100 \%$ & $57.1 \%$ \\
Uterine art. RI & $>0.82$ & $100 \%$ & $74.3 \%$ \\
HC/AC ratio & $>1.67$ & $80 \%$ & $91.4 \%$ \\
\hline
\end{tabular}


UA PI cut off value $>1.88$ could be differentiate placental cause from maternal and idiopathic causes with sensitivity $100 \%$ and specificity $57.1 \%$. Also. Placental cause could be differentiated from maternal and idiopathic causes by MCA PIcut off value $<1.12$ with sensitivity $100 \%$ and specificity $80 \%$. $\mathrm{C} / \mathrm{U}$ ratio cut off value $<0.63$ also, could be used to differentiate placental cause from maternal and idiopathic causes with sensitivity $100 \%$ and specificity $57.1 \%$.Also, uterine artery RI cut off value $>0.82$ could be used to differentiate placental cause from maternal and idiopathic causes with sensitivity $100 \%$ and specificity $74.3 \%$.HC/AC ratio cut off value $>1.67$ could be used to differentiate placental cause from maternal and idiopathic causes with sensitivity $80 \%$ and specificity $91.4 \%$

Table 7: Correlation between different Doppler and ultrasound indices

\begin{tabular}{|c|c|c|c|c|c|c|c|}
\hline & & UA PI & MCA PI & CU ratio & Ut. Art. RI & AFI & HC/AC ratio \\
\hline \multirow{2}{*}{ UA PI } & $\mathbf{r}$ & & $-0.934^{* * *}$ & $-0.937^{* *}$ & 0.27 & $-0.666^{* *}$ & $0.362^{*}$ \\
\hline & $\mathbf{p}$ & & 0.00 & 0.00 & 0.09 & 0.00 & 0.02 \\
\hline \multirow{2}{*}{ MCA PI } & $\mathbf{r}$ & $-0.934^{* *}$ & & $0.963^{* *}$ & -0.264 & $0.712^{* *}$ & $-0.324^{*}$ \\
\hline & $\mathbf{p}$ & 0.00 & & 0.00 & 0.1 & 0.00 & 0.04 \\
\hline \multirow{2}{*}{$\mathrm{C} / \mathrm{U}$ ratio } & $\mathbf{r}$ & $-0.937^{* *}$ & $0.963^{* *}$ & & -0.215 & $0.675^{* *}$ & -0.254 \\
\hline & $\mathbf{p}$ & 0.00 & 0.00 & & 0.1 & 0.00 & 0.1 \\
\hline \multirow{2}{*}{ UT. Art. RI } & $\mathbf{r}$ & 0.27 & -0.264 & -0.215 & & $-0.441^{* *}$ & $0.453^{* *}$ \\
\hline & $\mathbf{p}$ & 0.09 & 0.1 & 0.1 & & 0.004 & 0.003 \\
\hline \multirow{2}{*}{ AFI } & $\mathbf{r}$ & $-0.666^{* *}$ & $0.712 \mathrm{Y}^{* *}$ & $0.675^{* *}$ & $-0.441^{* * *}$ & & $-0.417^{* *}$ \\
\hline & p & 0.00 & 0.00 & 0.00 & $0.004^{* *}$ & & 0.007 \\
\hline \multirow[t]{2}{*}{ HC/AC ratio } & $\mathbf{r}$ & $0.362^{*}$ & $-0.324^{*}$ & -0.254 & $0.453^{* *}$ & $-0.417^{* *}$ & \\
\hline & $\mathbf{p}$ & 0.02 & 0.04 & 0.1 & 0.003 & 0.007 & \\
\hline
\end{tabular}

\section{Case presentation}

Pregnant female 28 years old, gravida 2, not diabetic or hypertensive, GA by LMP was 32 weeks and 5 days, GA by U/S was 30 weeks, EFW by U/S was 1549 \pm 226 grams $(30 \mathrm{w})$, UA PI $=6.78\left(>95^{\text {th }}\right.$ percentile $)$, MCA PI $=0.75\left(<5^{\text {th }}\right.$ percentile $), C / U$ Ratio
$=0.11$ (abnormal), BPP score $=4$ (abnormal), HC/AC Ratio = 1.04 (normal), AFI $=5$ (abnormal), she was delivered by CS. The outcome was perinatal death. Doppler examination of the fetus revealed brain sparring effect with REDF of the UA. 


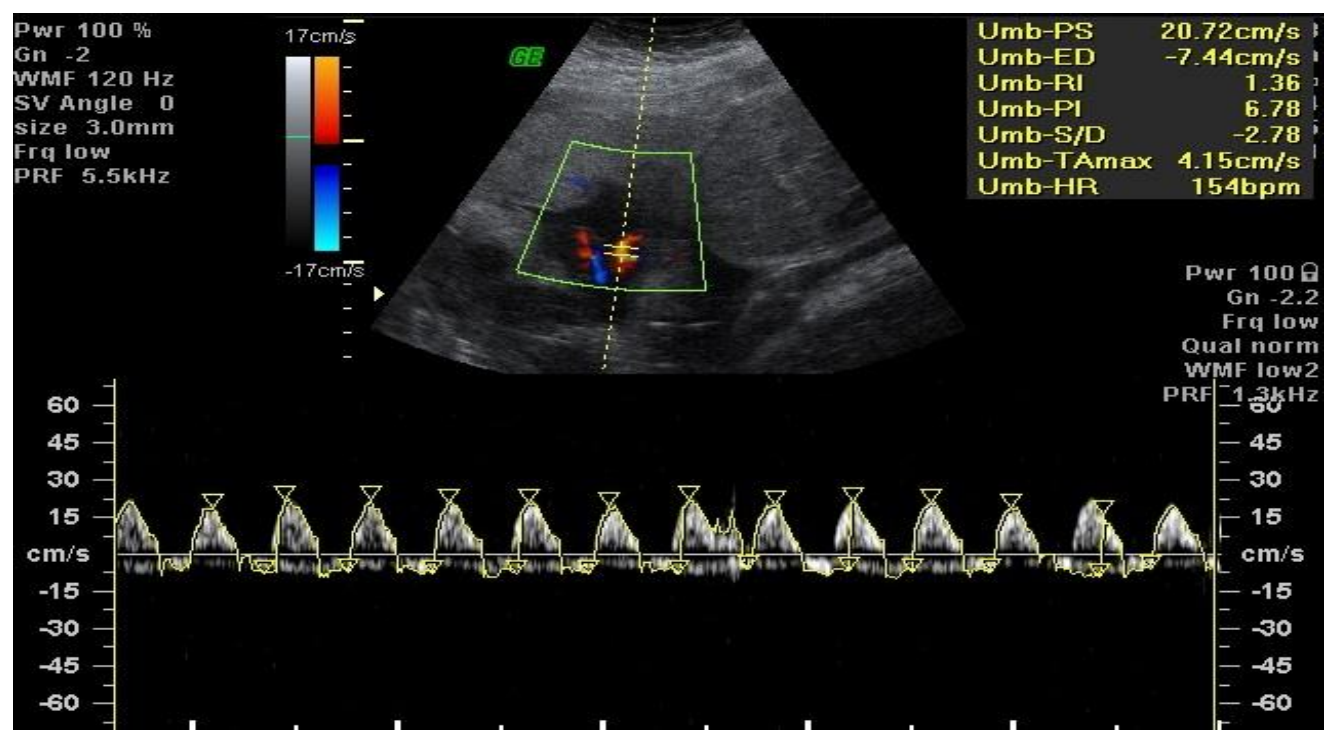

Fig. 2: Case 1, UA spectral analysis showing reversed flow.

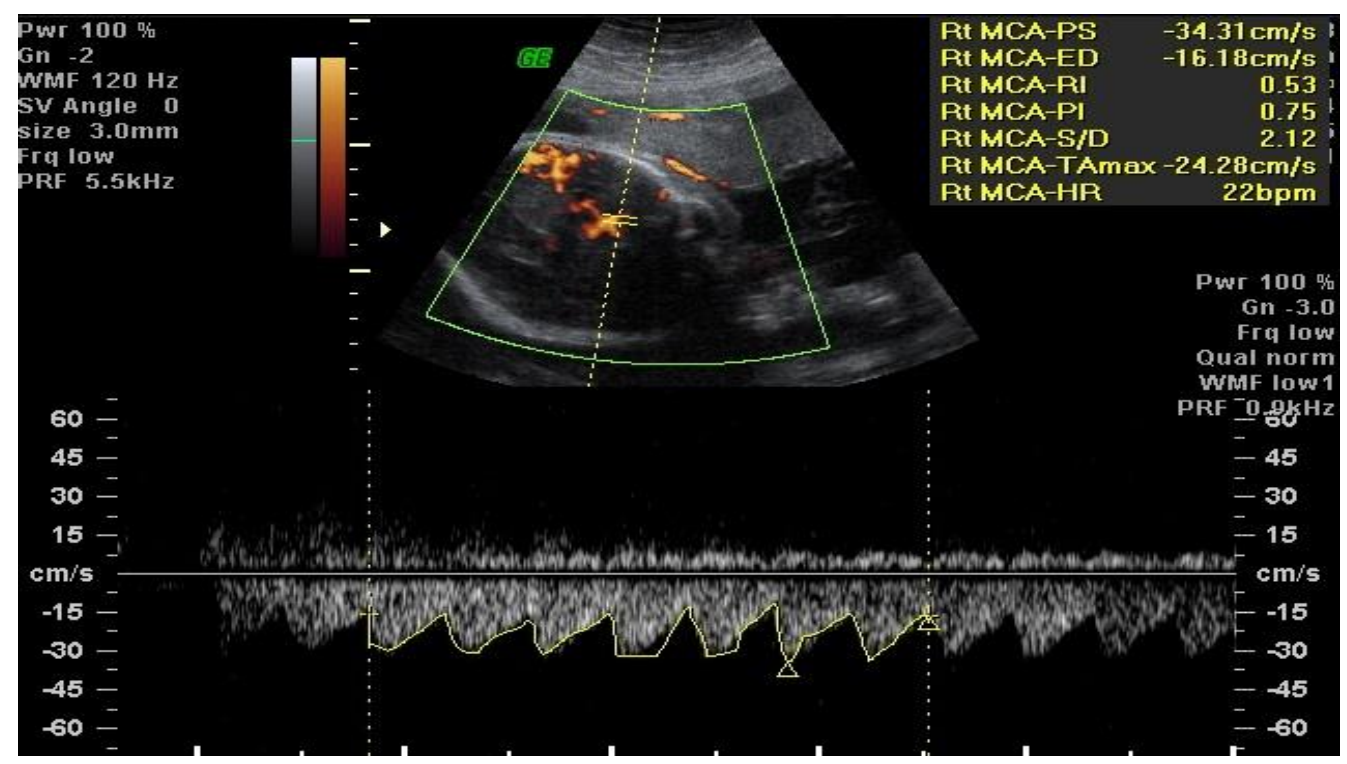

Fig. 3: Case 1, MCA Doppler showing abnormally high end diastolic flow and abnormal indices.

\section{Discussion}

Fetal growth restriction is most commonly secondary to utero-placental insufficiency, which leads in a stepwise, though not always predictable, manner to fetal hypoxia, acidaemia and, if delivery does not take place, intrauterine demise. Doppler blood flow velocimetry allows non-invasive assessment of the vascular impedance in the 
fetal circulation thereby inferring the degree of fetal hypoxia. (6)

An important consideration for all obstetrical caregivers is to ensure that reasonable efforts are made to identify and correctly manage pregnancies affected by intrauterine growth restriction. Neonatal mortality in both term and preterm neonates is significantly increased in those diagnosed with IUGR antenatally. (7)

Current challenges in the clinical management of IUGR include accurate diagnosis of the truly growth-restricted fetus, selection of appropriate fetal surveillance, and optimizing the timing of delivery. Despite the potential for a complicated course, antenatal detection of IUGR and its antepartum surveillance can improve outcomes. (8)

Studies have been hampered by the widespread practice of using the terms small for gestational age (SGA) and IUGR synonymously. SGA simply refers to a weight for gestation below a given threshold, but a significant proportion of smallness is due to constitutional or physiological causes. (9)

Doppler ultrasonography and biophysical profile scoring (BPS) are the principal surveillance tools in pregnancies complicated by placental vascular insufficiency and fetal growth restriction (FGR). These antenatal testing modalities aim to detect fetal compromise by evaluating fetal manifestations of altered oxygenation and metabolic status. (10)

Because no treatment has been demonstrated to be of benefit for FGR, the assessment of fetal well-being and timely delivery remains as the main strategy for management. Timing this intervention is complex because it requires balancing the risks of prematurity against those of continued intrauterine stay: death and multiple organ damage due to inadequate tissue perfusion. A reasonable goal is to allow the pregnancy to continue to the point just before fetal damage occurs, thereby minimizing the risks of both prematurity and organ injury from the disease. An important clinical question is if, and if so, how, this can be accomplished. (11)

The purpose of this study was to evaluate the usefulness of the pulsatility index (PI) of the umbilical artery (UA) and that of the middle cerebral artery (MCA), as well as the ratio of the MCA PI to the UA PI $(\mathrm{C} / \mathrm{U}$ ratio), in the diagnosis of intra-uterine growth restricted (IUGR) fetuses.

We studied 40 pregnancies that had been diagnosed clinically and ultrasonographically as intrauterine growth 
restriction (IUGR). All patients in the study underwent uniform antenatal assessment protocol that includes $\mathrm{C} / \mathrm{U}$ ratio , umbilical artery (UA), middle cerebral artery (MCA) and uterine artery ( UTA ) Doppler ultrasound studies. (12), conducted a study similar to this one comprised 90 pregnancies of 30-41 weeks gestation that had been diagnosed clinically as intrauterine growth retardation (IUGR) over a period of 1 year. The UA PI and the MCA PI as well as the $\mathrm{C} / \mathrm{U}$ ratio were calculated.

In this study, we found that the $\mathrm{C} / \mathrm{U}$ ratio was a better predictor of IUGR fetuses than either the MCA PI or UA PI alone. Abnormal C/U Ratio was found in 24 cases, 11 cases $(57.9 \%)$ due to maternal cause , 5 cases ( $100 \%$ ) due to placental cause , 8 cases ( $50 \%$ ) with idiopathic cause of the IUGR group. Abnormal UA PI was found in 25 cases, 11 cases $(57.9 \%)$ due to maternal cause , 5 cases $(100 \%)$ due to placental cause , 9 cases $(56.3 \%)$ with idiopathic cause of the IUGR group. Abnormal MCA PI was found in 26 cases, 11 cases $(57.9 \%)$ due to maternal cause , 5 cases ( $100 \%$ ) due to placental cause , 10 cases ( $62.5 \%$ ) with idiopathic cause of the IUGR group.

Of the 90 pregnancies in their study, 24 showed abnormal UA PI. Among these, 21 $(87.5 \%)$ were SGA and $19(79.2 \%)$ had adverse perinatal outcome. Of the four of the 90 pregnancies that showed abnormal MCA PI, all were SGA and had adverse perinatal outcome. Similarly, of the 20 out of 90 pregnancies that showed abnormal $\mathrm{C} / \mathrm{U}$ ratio $(<1.08)$, all $20(100 \%)$ were SGA and had adverse perinatal outcome. The results were correlated with parameters of fetal outcome. Inferences drawn from the study were: (1) The $\mathrm{C} / \mathrm{U}$ ratio is a better predictor of SGA fetuses and adverse perinatal outcome than the MCA PI or the UA PI used alone, (2) The UA PI can be used to identify IUGR per se and (3) The MCA PI alone is not a reliable indicator for predicting fetal distress.

\section{In this study}

- the UA PI Sensitivity $=100 \%$, specificity $=57.1 \%$

- For the MCA PI Sensitivity = $100 \%$, specificity $=80 \%$

- For the $\mathrm{C} / \mathrm{U}$ Ratio Sensitivity = $100 \%$, specificity $=57.1 \%$

The cut off value for the $\mathrm{C} / \mathrm{U}$ Ratio according to this study was $<\mathbf{0 . 6 3}$, our cut off point had a specificity of $57.1 \%$ and a sensitivity of $100 \%$.

Therefore, a normal MCA PI may not be an indicator of fetal well-being and MCA PI alone is not a reliable indicator. 
(13), conducted a prospective study to evaluate the value of the ratio of middle cerebral artery pulsatility index (MCA PI) to the umbilical artery pulsatility index (UA PI) for predicting of adverse perinatal outcome in the fetal growth restriction (FGR). The study population comprised 27 pregnant women who delivered FGR fetuses and 55 pregnant women whose fetuses were normal growth. The MCA PI, UA PI and MCA PI/ UA PI ratio were assessed. Abnormal MCA PI/ UA PI (CU ratio) was defined as the ratio $<1.08$. Of the 82 pregnant women, In FGR cases have high oligohydramnios, high cesarean section rate, lower GA at delivery, low birth weight and high rate of neonatal intensive care unit (NICU) admission compared with normal cases $(\mathrm{P}<0.05) .8$ out of 27 women with FGR showed abnormal CU ratio but only 2 in 55 fetuses in normal group ( $\mathrm{P}<0.001$ ).

They concluded that the MCA PI/ UA PI ratio could be used as the predictor for fetuses with growth restriction compared to normal cases.

UA and MCA were the target of research in many studies as regards their role in diagnosing IUGR, (15), (14), (11), (16), and (17), they all agreed with this study while (19) disagreed with this study.
A total of 145 singleton growth-restricted fetuses with abnormal umbilical artery pulsatility indexes, were studied. There were 4 fetal and 50 neonatal deaths. Neonatal death was increased in fetuses with umbilical artery reversed flow (15).

They concluded that fetuses with idiopathic growth restriction, low birth weight and umbilical artery reversed flow are associated with increased perinatal morbidity and mortality.

We found the same in this study, as we had 25 cases with abnormal UA PI ( 7 cases low EDF, 15 cases absent EDF, 3 cases reversed flow).

A prospective observational study was done on 70 pregnant women with growthrestricted fetuses confirmed by ultrasound who were followed up with Doppler studies of the umbilical artery and revealed that perinatal morbidity and mortality was significantly increased in the group with compromised umbilical artery and that AEDF and REDF had more morbidities, moreover perinatal mortality was also significantly increased in this group.

They concluded that in those fetuses with normal Doppler, pregnancy can be prolonged and that REDF is an indication for termination of pregnancy (14). 
In the study done before (11) there were 220 pregnant women with diagnosis of intrauterine growth restriction. They carried out in these women Doppler study of umbilical artery and middle cerebral artery. It was followed the perinatal outcome of the newborns. The Doppler indices of the umbilical artery were abnormal in all the cases of intrauterine growth restriction. The Doppler indices of the middle cerebral artery were abnormal in a small number of fetuses with perinatal complications.

They concluded that the Doppler study of the umbilical artery have better predictive value than the middle cerebral artery for predicting bad perinatal outcome. They recommend the assessment of umbilical artery as first choice in order to determine the well-being in fetuses with intrauterine growth restriction.

Another study also investigated the accuracy of fetal UA Doppler to predict the risk of compromise of fetal/neonatal wellbeing in a high-risk population by a systematic review and bivariate meta-analysis of 104 studies concluding that in a high-risk population, fetal umbilical artery Doppler is a moderately useful test to predict mortality and risk of compromise (16).

A study was conducted to measure the pulsatility index (PI) and resistive index of the middle cerebral artery with pulsatility and resistive index of the umbilical artery in predicting fetal growth restriction. A total of 60 pregnant women with a clinical history and grayscale-screened patients were taken for Doppler analysis, and a final comparison of accuracy of Doppler indices was done with perinatal outcome.

They concluded that the PI of the umbilical artery was more sensitive than the PI of the middle cerebral artery. Umbilical artery PI has the maximum overall diagnostic accuracy of $75 \%$, while the MCA PI had an overall diagnostic accuracy of $52.8 \%$ (17).

This study does not agree with the study carried out previously (18) which demonstrated that MCA PI measurement is better than UA PI in predicting the fetal outcome in intrauterine growth restriction. They conducted a prospective study on 121 subjects divided into two groups. The study group $(n=71)$ consists of high risk group of pregnant women with growth restricted fetuses. The control group $(n=50)$ consists of pregnant women with healthy fetuses. Both groups were evaluated by middle cerebral artery and umbilical artery velocimetry between 28 and 41 weeks of pregnancy. The subjects with high risk factors had more number of abnormal waveforms than those without high risk factors. The predictive 
value of Doppler PI for detecting abnormal fetal outcome was $94 \%$ in middle cerebral artery as against $83 \%$ for umbilical artery. The sensitivity was $71 \%$ for middle cerebral artery versus $44 \%$ for umbilical artery.

They concluded that middle cerebral artery Doppler indices were a better predictor for fetal outcome in IUGR when compared with umbilical artery in terms of sensitivity and predictive value.

Additional predictors that we also measured in this study are the HC/AC ratio and AFI.

$\mathrm{HC} / \mathrm{AC}$ ratio is used mainly to differentiate between symmetrical and asymmetrical IUGR in which this ratio is increased as a result of decreased AC due to severe IUGR which is almost of early onset, in other words this asymmetry occurs in severe and early onset IUGR, so elevated $\mathrm{HC} / \mathrm{AC}$ ratio is an indicator of degree of severity of IUGR. There is other predictor AFI of $5 \mathrm{~cm}$ or less was considered abnormal (oligohydramnios), while AFI more than 5 $\mathrm{cm}$ was defined as normal.

This study agrees with another one (19) which included $\mathrm{HC} / \mathrm{AC}$ ratio as well as AFI in their study. They conducted a prospective study on 100 patients of clinically suspected IUGR/high-risk pregnancies of 31-41 weeks. The cases were followed till delivery; the Doppler and grey scale findings were correlated with the birth weight of the baby. They found that the highest sensitivity was found to be of $\mathrm{HC} / \mathrm{AC}$ ratio, $(84.4 \%)$, the highest specificity of oligohydramnios and Cerebral/Umbilical Pulsatility ratio[C/U ratio] $(100 \%)$. The sensitivity of $\mathrm{C} / \mathrm{U}$ ratio was found to be $68.8 \%$. Fetal MCA had the lowest sensitivity $(7.7 \%)$.

They concluded that $\mathrm{HC} / \mathrm{AC}$ ratio is quite sensitive, and oligohydramnios is a highly specific parameter to diagnose IUGR. However, the former has lower specificity, and the latter has very poor sensitivity. The MCA PI alone is not sensitive at all, and should not be used for screening purposes in IUGR patients. Also, $\mathrm{C} / \mathrm{U}$ ratio is more sensitive than oligohydramnios and more specific than $\mathrm{HC} / \mathrm{AC}$ ratio and stands out as the best parameter of all to diagnose IUGR in the third trimester.

This study agrees with who studied 87 growth restricted fetuses from 28 to 42 weeks of gestation. The BPP and $\mathrm{C} / \mathrm{U}$ ratio were assessed twice a week.

They concluded that the BPP and the C/U ratio represent the useful indicators for early detection and assessment of fetal hypoxia. They may also be parameters for the prediction of neonatal neurosonography findings in newborns with IUGR (20). 
As regards correlation between different predictors $(\mathrm{C} / \mathrm{U}$ ratio, UA PI, MCA PI, AFI and $\mathrm{HC} / \mathrm{AC}$ ratio), our study revealed:

- There was a significant correlation between $\mathrm{C} / \mathrm{U}$ ratio and all predictors $(\mathrm{P}<$ 0.01 ) except $\mathrm{HC} / \mathrm{AC}$ ratio and uterine artery.

- UA PI showed significant correlation with predictors $(\mathrm{P}<0.01)$ except uterine artery.

- MCA PI showed significant correlation with predictors $(\mathrm{P}<0.01)$ except uterine artery.

- AFI correlation with different predictors was significant with $\mathrm{C} / \mathrm{U}$ ratio, and $\mathrm{UA} \mathrm{PI}$, MCA PI and $\mathrm{HClAC}$.

- HC/AC ratio showed significant correlation with predictors $(\mathrm{P}<0.01)$ except $\mathrm{C} \backslash \mathrm{U}$ ratio.

Results of this study were statistically analyzed and a ROC curve was calculated for the $\mathrm{C} / \mathrm{U}$ ratio, which has the best diagnostic accuracy as a screening test for diagnosing IUGR revealed a cut off point for this ratio of $<0.63$.

It should be noted that we have chosen this point in particular because we found that it has a high specificity of $57.1 \%$ and a sensitivity of $100 \%$.

\section{Conclusion}

Among the Doppler indices, the $\mathrm{C} / \mathrm{U}$ ratio is a better predictor of IUGR fetuses than either the UAPI or the MCA PI alone, with a high specificity and PPV. However, measurement of the UAPI (among all the Doppler indices) is enough to detect IUGR per se, probably because UAPI is a direct reflection of the resistance in the placental vascular bed. The MCA PI alone is not a reliable indicator, and its efficiency in predicting fetal distress is found to be lower than that of UAPI.

\section{References}

1. Sheridan C: "Intrauterine growth restrictiondiagnosis and management". Aust Fam Physician (2005), 34: 717-23

2. Chauhan SP, Gupta LM, Hendrix NW, Berghella, V. "Intrauterine growth restriction: comparison of American College of Obstetricians and Gynecologists practice bulletin with other national guidelines". American Journal of Obstetrics and Gynecology 2009;200:409.e1409.e6.

3. Du Plessis A. J., "Cerebral Blood Flow and Metabolism in the Developing Fetus", MPH, Clinics in Perinatology Volume 36, Issue 3 (September 2009)

4. Hadlock F. P., Harrist R. B., and Sharman R. S., "Estimation of fetal weight with the use of head, body, and femur measurements - a prospective study," American Journal of Obstetrics and Gynecology, 1985, vol. 151, no. 3, pp. 333-337.

5. Odibo AO, Riddick C, Pare E, Stamilio DM, Macones GA, "Cerebroplacental Doppler ratio and adverse perinatal outcomes in intrauterine growth restriction: evaluating the impact of using 
gestational age-specific reference values". J Ultrasound Med 2005;24:1223-8.

6. Talmor A, Daemen A, Murdoch E, MissfelderLobos H, Timmerman D, Bourne T,...et "Defining the relationship between fetal Doppler indices, abdominal circumference and growth rate in severe fetal growth restriction using functional linear discriminant analysis". J R Soc Interface 10: 20130376.

http://dx.doi.org/10.1098/rsif.2013.0376

7. Lausman A and Walker $M$ : "Screening, Diagnosis, and management of Intrauterine Growth Restriction" J Obstet Gynaecol Can 2012;34(1):17-28.

8. Society for Maternal-Fetal Medicine (SMFM) Clinical Guideline "Doppler assessment of the fetus with intrauterine growth restriction", AJOG 2012, $\quad$ http://www.ajog.org/article/S00029378(12)00051-8/.

9. Cruz-Martinez R, Figueras F, Hernandez-Andrade E, Puerto B \& Gratac'os E: "Longitudinal brain perfusion changes in near term small-for gestational-age fetuses as measured by spectral Doppler indices or by fractional moving blood volume". Am J Obstet Gynecol (2010); 203: 42.e1-6.

10. Baschat AA\& Harman CR.: "Discordance of arterial and venous flow velocity waveforms in severe placenta-based fetal growth restriction". Ultrasound Obstet Gynecol (2011); 37:369-70.

11.Espinoza J, Romero R, Mee Kim Y, Kusanovic JP, Hassan S, Erez O, et al: "Normal and abnormal transformation of the spiral arteries during pregnancy". J. Perinat. Med. (2006); 34 $447-458$

12. Bano S, Chaudhary V, Pande S, Mehta V \& Sharma A: "Color Doppler evaluation of cerebral-umbilical pulsatility ratio and its usefulness in the diagnosis of intrauterine growth retardation and prediction of perinatal outcome". Indian J Radiol Imaging (2010);(1):20-5

13. Nanthakomon T. and Somprasit C., "The value of middle cerebral artery-umbilical artery pulsatility index ratio in prediction of severe fetal growth restriction". Thammasat Medical Journal, JulySeptember 2010, Vol. 10 No. 3.

14. Malhotra N, Chanana C, Kumar S, Roy K \& Sharma JB: "Comparison of perinatal outcome of growth-restricted fetuses with normal and abnormal umbilical artery Doppler waveforms". Indian J Med Sciences (2006); (8): 311-317.

15. Mari G., Hanif F., Kruger M., Cosmi E., Santolaya-Forgas J., and Treadwell M. C., "Middle cerebral artery peak systolic velocity: a new Doppler parameter in the assessment of growth-restricted fetuses," Ultrasound in Obstetrics and Gynecology, 2007, vol. 29, no. 3, pp. 310-316.

16. Morris RK, Malin G, Robson SC, Kleijnen J, Zamora J \& Khan KS: "Fetal umbilical artery Doppler to predict compromise of fetal/neonatal wellbeing in a high-risk population: systematic review and bivariate meta-analysis". Ultrasound Obstet Gynecol (2011); 37: 135-142

17. Khanduri Sachin, Parashari Umesh C., Bashir Shazia, Bhadury Samarjit, Bansal Anurag, "Comparison of Diagnostic Efficacy of Umbilical Artery and Middle Cerebral Artery Waveform with Color Doppler Study for Detection of Intrauterine Growth Restriction". The Journal of Obstetrics and Gynecology of India (July-August 2013) 63(4):249-255

18. Hemlata Dhand, Kumar Kansal Hemant, Anupama Dave, "Middle Cerebral Artery Doppler 
Indices Better Predictor for Fetal Outcome in

IUGR". The Journal of Obstetrics and Gynecology of India March / April 2011 pg 166 171

19. Malik Rajesh and Saxena Agamya, " Role of Colour Doppler Indices in the Diagnosis of Intrauterine Growth Retardation in High-Risk Pregnancies". The Journal of Obstetrics and Gynecology of India (January-February 2013) 63(1):37-44
20. Habek D, Salihagić A, Jugović D \& Herman R: "Doppler cerebro-umbilical ratio and fetal biophysical profile in the assessment of peripartal cardiotocography in growth-retarded fetuses". Fetal Diagn Ther. (2004); 22(6):452-6.

To cite this article: Medhat M. Refaat, Ahmed E. Shalaan, Radwa N. Afifi. Role of Ultrasound and Color Flow Doppler in Diagnosis of Intrauterine Growth Restriction. BMFJ 2021;38(2):725740. DOI: 10.21608/bmfj.2021.16924.1056 